\title{
LEVANTAMENTO DO CONTEÚDO DIDÁTICO SOBRE O SOLO E SUAS INTERFACES NA REGIÃO DE FEIRA DE SANTANA
}

\author{
$\underline{\text { Alix dos Santos Costa }}{ }^{1}$; Tainã Cádija Almeida de Mamede ${ }^{2}$; Joselisa Maria \\ Chaves $^{3}$
}

1. Bolsista PEVIC, Graduanda em agronomia e membro do grupo pet geografia-agronomia da Universidade Estadual de Feira de Santana, e-mail: alixfsa@ hotmail.com

2. Professora orientadora e pesquisadora do grupo pet geografia-agronomia. Departamento de Exatas, Universidade Estadual de Feira de Santana, e-mail: tai_bio@yahoo.com.br

3. Professora co-orientadora e tutora do grupo pet geografia-agronomia, Departamento de

Exatas. Universidade Estadual de Feira de Santana, e-mail: joselisa@uefs.br

PALAVRAS-CHAVE: Pesquisa bibliográfica, pedologia, agronomia

\section{INTRODUÇÃO}

O levantamento bibliográfico é essencial para produção de trabalhos científicos como artigos, teses, dissertações, monografias, etc. Consiste na pesquisa utilizando diferentes fontes didáticas como livros, revistas, artigos entre outros a respeito de um tema especifico. O levantamento bibliográfico exige dos estudantes dedicação na busca por fontes confiáveis e que disponibilizem os dados necessários para realização do trabalho. Deve-se considerar que não se restringe apenas em encontrar o tema, exige também encontrar fontes que sejam adequadas ao assunto que se pretender escrever, ou seja, a pesquisa do tema solos fornece uma infinidade de informações, sendo que dessas uma menor parte realmente atende o que se deseja, dessa forma um tema tem um subtema, sendo assim o tema solo vai ter um subtema que vai direcionar o que de fato se pretende encontrar, podendo ser: solos de uma determinada região; tipos de solos de um município, etc. Pesquisas bibliográficas na construção de um trabalho acadêmico requer uma maior disponibilidade de tempo e enriquece o trabalho.

Para facilitar a busca por diversos assuntos acadêmicos e evitar o desperdício de tempo existem bibliotecas virtuais que auxiliam os estudantes em suas consultas. No Brasil tem-se a biblioteca do Portal de periódicos da CAPES (Coordenação de Aperfeiçoamento de Pessoal de Nível Superior) criada em 1990 a qual fornece as instituições de ensino e pesquisa no Brasil o melhor da produção científica internacional, com um acervo de mais de 53 mil títulos com texto completo, 129 bases referenciais, 11 bases dedicadas exclusivamente a patentes, além de livros, enciclopédias e obras de referência, normas técnicas, estatísticas e conteúdo audiovisual.

Com o objetivo de auxiliar estudantes principalmente os alunos de geografia e agronomia da Universidade Estadual de Feira de Santana - UEFS foi realizado um levantamento de artigos, livros e revistas da biblioteca Julieta Carteado localizada na UEFS, do portal CAPES, trabalhos apresentados na SEMIC (Semana de Iniciação Cientifica - Uefs), a respeito de temas relacionados aos solos do Município de Feira de Santana. A tabela de dados foi disponibilizada no blog sensor agro e na base de dados (GEOBASE), com intuito de auxiliar os estudantes na realização de trabalhos 
acadêmicos e escolares a respeito desse tema, otimizando o tempo da pesquisa bibliográfica.

\section{MATERIAL E MÉTODOS OU METODOLOGIA (ou equivalente)}

O método utilizado consistiu no levantamento de livros, artigos e demais conteúdos didáticos que falem sobre solos da cidade de Feira de Santana-Ba. O levantamento foi realizado na biblioteca Julieta Carteado e no Portal Periódico da CAPES, assim como nos anais da Semana de Iniciação Cientifica da UEFS (SEMIC). Esses conteúdos são importantes para os estudantes em especial os alunos de agronomia e geografia que tem na sua grade curricular disciplinas como: pedologia, geociências, física do solo, química e fertilidade do solo, manejo e conservação da agua e do solo e geologia geral. Vale ressaltar que a tabela de dados foi construída com a sinalização do link cujo conteúdo acerca de solos foi encontrado. Isso irá facilitar a busca acadêmica pelos estudantes, otimizando assim o tempo de pesquisa. A população externa também poderá acessar o quadro de conteúdo didático, uma vez que estarão disponíveis na base de dados (GEOBASE), e também no blog denominado "sensor agro".

\section{RESULTADOS E/OU DISCUSSÃO (ou Análise e discussão dos resultados)}

No levantamento bibliográfico realizado constatou-se a existência de diversos artigos que retratam informações a respeito dos solos da cidade de Feira de Santana-Ba, sendo esses abordados principalmente pelos cursos de agronomia, geografia e engenharia civil da Universidade Estadual de Feira de Santana. Maior parte dos conteúdos encontrados foram desenvolvidos por estudantes da UEFS em conjunto com os professores, principalmente do departamento de ciências exatas (DEXA), mas também foram encontrados artigos referentes ao município realizado por outras instituições de ensino, como a UESB. Isso mostra que a cidade de Feira de Santana apresenta potencial de estudo para a realização de pesquisas com este cunho cientifico. Neste sentido pode-se constatar com este trabalho que o conteúdo sobre solos no município foi mapeado, organizado e disseminado para atender condições cognitivas melhores a fim de: evitar a duplicação de pesquisas, assim como reaproveitar e replicar pesquisas em diferentes escalas e contextos observando assim possíveis falhas nos estudos realizados (GALVÃO, 2010).

Foi verificado que na biblioteca não possui literaturas variadas que retratem e tragam informações a respeito dos solos de Feira de Santana, mas possui alguns livros a respeito de solos em geral, os quais são muito utilizados pelas disciplinas citadas anteriormente. Sendo assim de grande importância para realização de fundamentação teórica para os estudantes, em especial os que cursam agronomia, geografia, química, biologia e também engenharia civil. Foram feitos dois quadros de conteúdo didático com 46 artigos e 21 livros. O quadro de artigos consta aqueles encontrados organizados por título do artigo, nome do autor ou autores, link, palavras chaves, data que foram encontrados e a base de dados que foi localizado. Após os artigos terem sido encontrados foi realizada uma verificação para constar se algum deles abordavam praticas agroecológicas e sustentável em relação ao manejo dos solos do município, porém nenhum dos textos encontrados era voltado para essa proposta. Uma amostra com alguns exemplares consta no quadro 1. O quadro de livros está listado com aqueles encontrados na biblioteca da UEFS com o conteúdo de solos em geral organizados em 
ordem crescente do ano de publicação. Uma amostra com alguns livros encontrados encontra-se no quadro 2. No levantamento bibliográfico realizado na biblioteca da UEFS notou-se que os livros estão presentes em diversidade, porém não tem quantidade suficiente para atender a quantidade de alunos da que assim necessitem. Verificou-se também a pouca existência de livros recentes na biblioteca sobre solos em geral, sendo os mais recentes encontrados a respeito deste tema: 19 lições de pedologia (2011); Elementos da Natureza e Propriedades dos Solos (2012); Solo, planta e atmosfera: conceitos, processos e aplicações (2012).

Quadro 1- Amostra de alguns artigos retirada do "Quadro de conteúdo didático sobre solos no município de Feira de Santana que apresenta um total de 46 artigos"

\begin{tabular}{|c|c|c|c|c|c|}
\hline Título do artigo & Autor & Link & $\begin{array}{c}\text { Palavras- } \\
\text { chave }\end{array}$ & Data & $\begin{array}{c}\text { Base } \\
\text { de } \\
\text { dados }\end{array}$ \\
\hline $\begin{array}{l}\text { Descrição de perfis } \\
\text { de solos no distrito de } \\
\text { Bonfim de feira - } \\
\text { feira de Santana, } \\
\text { Bahia }\end{array}$ & $\begin{array}{l}\text { Jarine } \\
\text { Araújo } \\
\text { de } \\
\text { Almeida. } \\
\text { Et al }\end{array}$ & $\begin{array}{l}\text { https://www.rev } \\
\text { istas.ufg.br/ateli } \\
\text { e/article/view/8 } \\
\underline{584 / 6086}\end{array}$ & $\begin{array}{l}\text { Solo, } \\
\text { Propriedades } \\
\text { Morfológicas, } \\
\text { Bonfim de } \\
\text { Feira. }\end{array}$ & $20 / 03 / 2018$ & CAPES \\
\hline $\begin{array}{ll}\text { Caracterização } & \\
\text { geoambiental do } \\
\text { campus da } \\
\text { universidade } \\
\text { Estadual de feira de } \\
\text { Santana através de } \\
\text { mapeamento } \\
\text { Geotécnico }\end{array}$ & $\begin{array}{l}\text { Juliele } \\
\text { Nascime } \\
\text { nto Jesus. } \\
\text { Et al }\end{array}$ & $\begin{array}{l}\text { http://periodico } \\
\text { s.uefs.br/index. } \\
\text { php/semic/articl } \\
\text { e/view/2269/17 } \\
\underline{49}\end{array}$ & $\begin{array}{l}\text { UEFS; } \\
\text { Mapeamento; } \\
\text { Geoambiental. }\end{array}$ & $20 / 03 / 2018$ & SEMIC \\
\hline $\begin{array}{l}\text { Caracterização } \\
\text { mineralógica da } \\
\text { fração areia fina nos } \\
\text { argissolos do campus } \\
\text { da uefs, feira de } \\
\text { santana - BAHIA }\end{array}$ & $\begin{array}{l}\text { Tamires } \\
\text { Moraes } \\
\text { Oliveira; } \\
\text { Marilda } \\
\text { Santos } \\
\text { Pinto e } \\
\text { Andrea } \\
\text { Sander }\end{array}$ & $\begin{array}{l}\text { http://www.xvis } \\
\text { emic.esy.es/arq } \\
\text { uivos/sessao- } \\
\text { iv/tamires- } \\
\text { moraes- } \\
\text { oliveira.pdf }\end{array}$ & $\begin{array}{l}\text { Mineralogia, } \\
\text { Solos, UEFS. }\end{array}$ & $14 / 11 / 2017$ & SEMIC \\
\hline
\end{tabular}

Quadro 2- Amostra de alguns livros encontrados na Biblioteca Julieta Carteado e retirada do "Quadro de conteúdo didático sobre solos no município de Feira de Santana que apresenta um total de 21 livros"

\begin{tabular}{|c|c|c|c|c|}
\hline Titulo & Autor & $\begin{array}{l}\text { Ano de } \\
\text { publicação }\end{array}$ & Exemplares & $\begin{array}{l}\mathbf{N}^{\circ} \text { de } \\
\text { chamada }\end{array}$ \\
\hline Fertilidade do solo & $\begin{array}{c}\text { Fernando S. } \\
\text { Coelho e Flavio } \\
\text { Verlengia }\end{array}$ & 1973 & 1 & 631.4 C616 \\
\hline $\begin{array}{c}\text { A agua, o solo e a } \\
\text { planta }\end{array}$ & $\begin{array}{c}\text { E. J. Winter; } \\
\text { traduzido pelos } \\
\text { professores Klaus } \\
\text { Reichardt e Paulo } \\
\text { L. Libardi }\end{array}$ & 1976 & 5 & $581.5 \mathrm{~W} 745$ \\
\hline Os solos agrícolas & $\begin{array}{c}\text { S. Henin, R. Gras, } \\
\text { G. Monnier; trad. } \\
\text { de Orlando } \\
\text { Valverde }\end{array}$ & 1976 & 2 & $631.4 \mathrm{H} 438$ \\
\hline
\end{tabular}




\begin{tabular}{|c|c|c|c|c|}
\hline $\begin{array}{l}\text { Elementos da Natureza } \\
\text { e Propriedade dos solos }\end{array}$ & $\begin{array}{c}\text { Nyle C. Brady; } \\
\text { trad. de Antônio B. } \\
\text { Neiva Figueiredo } \\
\text { Filho }\end{array}$ & 2012 & 4 & $631.4 \mathrm{~B} 79$ \\
\hline
\end{tabular}

\section{CONSIDERAÇÕES FINAIS (ou Conclusão)}

Foram encontrados um número significativo acerca dos trabalhos de solos na cidade de Feira de Santana, com ênfase aos solos do campus da UEFS. Isso irá facilitar a busca acadêmica pelos estudantes, otimizando assim o tempo de pesquisa. Os quadros com os conteúdos didáticos encontram-se disponível na base de dados GEOBASE (www.geobase.uefs.br), e também no blog sensor agro, (https://sensoragro.wordpress.com/), estando assim esses dados acessíveis para a comunidade acadêmica e escolar em geral.

\section{REFERÊNCIAS}

GODOY, C. Levantamento Bibliográfico. 2011. Disponível em: <http://cidagodoy.blogspot.com/2011/03/levantamento-bibliografico.html>. Acesso em: 20 ago. 2018

GALVÃO, M, C, B. O levantamento bibliográfico e a pesquisa científica. 2010. Disponível em: <http://www2.eerp.usp.br/Nepien/DisponibilizarArquivos/Levantamento_bibliografico _CristianeGalv.pdf>. Acesso em: 20 ago. 2018

CAPES Coordenação de Aperfeiçoamento de Pessoal de Nível Superior. Portal de Periódicos. Brasília: CAPES. Disponível em: http://www.periodicos.capes.gov.br/portugues/index.jsp Acesso em: 20 de agosto de 2018 